\title{
LA IMPORTANCIA DE LA EDUCACIÓN ESTÉTICA
}

Rosa María Margarit Mitja

La educación de los niños y jóvenes se ha enfatizado, desde hace siglos, en los criterios de verdad y falsedad por encima de cualquiera otros, obligando, a menudo, a los estudiantes a hacer un serio esfuerzo imaginativo, y casi un acto de fe, para aceptar el " $2+2=4$ ", para citar un simple ejemplo. Criterios que, con pretensión de evidencia y claridad, se convirtieron en indiscutibles. La sensibilidad ante las cosas, los valores y virtudes quedaban relegadas, en el mejor de los casos, al ideario del centro educativo. Este ejercía, casi exclusivamente, la formación del intelecto en el ámbito de la razón instrumental en el más reducido de sus aspectos. Se suponía que, desde esa plataforma, las grandes cabezas forjarían un mundo mejor. Esta idea del progreso humano, apoyada exclusivamente en la razón, estaba presente en la herencia hegeliana.

Hoy, muchos educadores que abogan por ampliar el concepto educativo atreviéndose a fomentar otras opciones 
de aprendizaje en niños y jóvenes, sin excluir la del intelecto. Junto a todo lo anterior, la belleza está irrumpiendo con fuerza. Lo bello, del latín bellus, significa elegante, amable. Denominamos bello a un determinado ideal, distinto de lo sublime, aplicable a un hermoso paisaje, un buen caballo o un excelente coche. Así, lo bello corresponde a un ideal estético y tendrá el valor que le queramos otorgar o promover.

La idea de que una persona, por ser sensible a lo bello, es blanda e inestable, que sueña y no tiene los pies sobre la tierra, ha sido, en muchos casos, abandonada. Quizás por la constatación de que alguien con sentido de lo bello y lo feo, tiene un criterio más claro de lo que es bueno y de aquello que no lo es. Aquella razón soberbia, sola y árida, donde lo bueno queda reducido a lo lógico, es lo que la educación estética pretende cambiar.

\section{La educación estética}

La educación estética procura el fomento de la conciencia estética, en general, y de la artística, en particular, de los seres humanos en un contexto social determinado. Esto, en cuanto a la comprensión y valorización de los objetos estéticos, así como a la actividad que, dentro del terreno artístico, se genere. Toda educación estética responde a las exigencias y posibilidades dadas en una sociedad y una cultura determinadas, desarrollándose mediante las instituciones educativas.

Esta educación se propone el florecimiento de la sensibilidad de las personas, la ampliación del horizonte estético en que se desenvuelven y el fortalecimiento del papel que desempeña en la vida real este tipo de comportamiento. Por lo tanto, supone una serie de conocimientos acerca del modo específico en que los seres humanos deben relacionarse con la realidad, justamente 
a través de la apropiación estética del mundo, y del arte como forma fundamental de tal apropiación. Sin embargo, aparte del arte, lo estético puede hacerse presente en las más diversas actividades humanas, sean actos deportivos, desfiles, manifestaciones políticas, etc., aun aquellas que se realicen sin la intención expresa de provocar un efecto de esta naturaleza. En todos los casos, se trata de objetos y procesos que, ya sea de un modo dominante o secundario, constante o transitorio, entran en el universo estético y que, siendo sensibles por su forma, proveen significados.

El universo estético no es finito o cerrado y no puede ser establecido a priori, de una vez y para siempre. Sus límites varían de acuerdo con los ideales, valores y convenciones dentro de un contexto social y cultural dado. Algo que ayer pudo ser antiestético, con el transcurrir histórico puede llegar a pertenecer a este universo, y viceversa.

Actualmente, ¿qué lugar ocupa el arte en la esfera de lo estético? Ya Hegel, en las primeras décadas del S. XIX, había anunciado la muerte del arte y, aun hoy, se sigue hablando de ello; pero, a pesar del desarrollo científicotécnico y de los factores económicos y políticos -contrarios, muchas veces, a la creatividad artística- el arte muestra una vitalidad que lo hace permanecer en una posición de privilegio en nuestra sociedad. El lugar del arte se encuentra donde predomina la función estética, lo que no quiere decir que no cumpla con otras funciones extras (ideológicas o sociales).

La función estética es predominante en dos sentidos:

1. La obra artística es creada para suscitar un efecto estético puesto de manifiesto en la relación contemplativa.

2. En cuanto a lo extraestético: la obra artística solo puede cumplirse estéticamente. 
Lo estético se da en la obra de arte, pero es posible, también, fuera de ella. Está en la naturaleza. Los objetos naturales se insertan en lo humano: la naturaleza en sí se transmuta en una humanizada. Sin embargo, el ser humano no siempre ha estetizado la naturaleza. Y si lo ha hecho, ha sido en el curso de un largo proceso histórico-social cuya base reside en su relación práctico-productiva con ella.

Lo estético ingresa en nuestra vida cotidiana por medio de la mayoría de nuestros actos y actividades, donde son utilizados diversos objetos que satisfacen nuestras necesidades y que, como objetos usuales, a partir de su capacidad de satisfacción de esas necesidades, reciben su valor correspondiente. Cuando estos objetos adquieren un valor de uso, no están destinados a cumplir una función estética; su forma se adecua a su fin utilitario. En el marco de la vida cotidiana, los edificios, calles, parques, estadios, etc., son objetos que cumplen una función práctica puesto que contribuyen a satisfacer una necesidad determinada, utilitaria o instrumental.

La historia de la humanidad nos muestra que los seres humanos no se han limitado a aceptar los objetos cotidianos por su utilidad, sino que, en su presentación, les han sido introducidos elementos formales que rebasan las simples exigencias práctico-utilitarias. Se espera de ellos que no solamente sean útiles, sino que agraden al ser contemplados: por lo tanto, al valor de uso se agrega la función estética, en virtud de lo cual un objeto cotidiano puede ser bello sin dejar de ser útil.

En las sociedades industriales desarrolladas, o aún en las nuestras, donde los consumidores se sienten cada día más asediados por los objetos de consumo que los asaltan con el empuje de la publicidad desenfrenada, es reconocible la tendencia a estetizar los objetos de consumo, tendencia que no debemos separar de la estructura económica y social 
donde se dan y que el criterio que regula la producción de ellos es, con toda seguridad, primordialmente económico. De allí que podamos hablar de una estética industrial que rompe con la tradicional caracterizada, precisamente, por la disociación de lo estético con lo útil.

En conclusión, la educación aquí promovida, procura elevar y ampliar la conciencia y la actividad de los seres humanos con el universo estético.

\section{La educación estética en Costa Rica}

En 1924, Rogelio Sotela ${ }^{1}$ postulaba la necesidad de implementar la educación estética entre los jóvenes. En su tesis sostenía que el concepto de "utilidad de la belleza" habría hecho mucho daño entre ellos: "Se dice que lo bello no es útil y es que se piensa en una utilidad inmediata" 2 .

Cuando se trata de educar, casi siempre lo primero que se discute es acerca de la utilidad de tal conocimiento; el fin práctico que la educación persigue. Pero, el fin práctico de la educación estética es secundario y: "(...) tiende hacia la formación de los sentimientos altruistas o sociales" 3 .

ParaSotela todo depende del uso que se le da a la palabra "útil". Pues, en la naturaleza no existe nada inútil y menos tratándose de una fuente de salud o de regocijo interior. Por otro lado, Sotela resalta el hecho de que la educación estética busca que el individuo comprenda la armonía del universo desde lo más íntimo hasta lo más grande, mirando serena y armoniosamente lo que ocurre alrededor de él: "La estética es amonia, como es armonía la belleza"4.

Poeen, abogado y educador costarricense (1894-1943).

SOTELA. Rogelio. La educación estetica. En: Repertorio Americano. Tumo XI, 29 de setiembre de 1924, $\mathrm{N}^{*} 4$, pp. 51.52 .

libis. .51 .

- Ibid, p 51 . 
En su criterio, si la belleza es fulgor de la verdad, como la llamó Platón, o símbolo del bien, como la vió Kant, o el arte de lo bello, cualquiera que fuera su definición, debería dársele más importancia a su estudio y no tenerla tan descuidada. Afirma, además, que la educación como proceso de desenvolvimiento individual necesita el desarrollo de una cultura integral que se propicie y complemente con una educación holística, física, estética y moral. Esto es, el desarrollo de la inteligencia, del cuerpo, del sentimiento y de la voluntad. Nos dice que: "La educación estética debe ser integral, procurando hacer sentir la parte bella de cada actividad, de cada asignatura"s.

Opina, también, que es fundamental que todo aprendizaje despierte la simpatía en el alumno por la asignatura que va a conocer. Si el aprendizaje se realiza de modo agradable, se aprenderá más y más rápidamente. Debe darse un acercamiento entre profesores y alumnos para que la verdadera educación se establezca. Si la simpatía despierta en los alumnos, vendrán la comprensión y el interés hacia la persona que les comunica. Los sentimientos estéticos pertenecen al ámbito educativo y la influencia de la educación como factor esencial, sea individual o social, es indiscutible.

Sotela recomienda para el desarrollo de las aptitudes estéticas los siguientes ejercicios:

1. Ejercicios manuales: escritura, dibujo, modales.

2. Ejercicios físicos: cantos, marchas, etc.

3. Educación de los sentidos: cultivo del campo sensorial.

4. Cultivo de la observación: intuición, concepción, etc.

${ }^{3}$ Ibíd., F. 52. 
5. Gusto por la asignatura: acuerdo de lo útil y lo bello.

6. Ejercicios de educación estética en todas las asignaturas.

7. Clases especiales de orientación estética.

La actitud de Sotela ante el universo estético es hacernos ver que el mismo no es solo patrimonio exclusivo de los artistas, sino, más bien, patrimonio de todos.

\section{Valoración final}

Desde que Rogelio Sotela hizo las anteriores reflexiones, han pasado muchos años. Algunas de sus sugerencias hoy nos pueden parecer ingenuas, atrasadas y hasta superadas, pero su disposición sigue siendo válida en la medida en que quiere inyectarle a la educación sentido moral y sensibilidad; en la que los sentimientos, valores e información inculcados a niños y jóvenes, procuren personas más felices.

Reconocer lo bello conduce a valorar lo existente, lo que es, y amarlo tal cual. Este reconocimiento humilde de la realidad es lo que engendra la verdadera sabiduría, incitando a nuestra inteligencia a trabajar para mejorar si es que contamos con posibles deficiencias; para construir una realidad más armónica que permita vivir felizmente y, por supuesto, evitar al máximo actuar en detrimento de cualquier persona.

Educar la libertad de las personas según la belleza, desarrollándola sabiamente, permite llegar a la realización del amor auténtico, libre y lúcido.

La finalidad de la educación estética consiste en la plena realización de las potencialidades de los estudiantes mediante el desarrollo integral de sus personalidades, su integración a la vida familiar y social; una preparación adecuada para que la persona responda en el futuro, de una 
forma satisfactoria, a las necesidades propias, de su familia y de la sociedad en general.

Con esta orientación se busca desarrollar las capacidades emocional, intelectual, social y estética de los alumnos mediante la educación activa, participativa, integral y crítica, estimulando el autodesarrollo dentro de un ambiente seguro, lleno de amor, de comprensión, respeto a la persona y-porqué no- divertido.

Hoy en día, puede percibirse un ambiente vacío y absurdo por cuanto la educación está más dirigida a informar que a orientar. Considerar la educación "un fenómeno humano", encaminada a formar seres "libres, activos, críticos, autocríticos y conscientes", en familia y en sociedad, seguirá teniendo validez siempre y cuando no se descuide preparar las personas para la vida actual con sus complejidades, demandas de estudio en el ámbito universitario y ambiente de trabajo para el futuro.

La educación se ve beneficiada no solo por los estudios estéticos sino por la práctica de las disciplinas artísticas. Por ejemplo, sabemos que los niños y los jóvenes poseen un sentido lúdico que pudieran proyectar a través del teatro; o, digamos, el patinaje artístico, deporte que requiere alta precisión y elegancia estética; o el mismo fútbol, de siempre y de todos; igualmente, la gimnasia deportiva en la cual es posible crear coreografías y figuras al compás de la música. Otro ejemplo: en los talleres musicales, donde las melodías surgidas de los instrumentos, entrelazan conocimiento y amistad. También, las visitas a salas y museos, y el contacto con nuestros artistas, son otras formas de aproximación al conocimiento y a la experiencia estética. Tampoco son despreciables los talleres informáticos en donde el usuario participa con sus conocimientos del uso inteligente de la tecnología, pudiendo discernir mejores pasos en cada caso por resolver, comprendiendo que ella es una herramienta 
de suma importancia en el mundo de hoy. Y muchas posibilidades más.

De complementar la formación estética y la práctica artística con actividades deportivas, estaremos ampliando el mundo de posibilidades de bienestar para la infancia, la adolescencia y la juventud y, por ende, para los futuros seres adultos.

Por tanto, la experiencia estética es un fenómeno que, al igual que el lenguaje, afecta la totalidad del género humano y que, sin lugar a dudas, debe ser objeto de atención educativa.

En resumen, el objetivo de la educación estética es contribuir para lograr el máximo desarrollo de las potencialidades espirituales y culturales de las personas, ampliando sus capacidades creadoras y realizando, de manera integral, su proceso de formación general. Ha de atender, de manera sistemática, el desarrollo de la creatividad, la imaginación, la sensibilidad y la capacidad de goce estético, todo mediante el conocimiento y práctica de las artes y el fomento de actividades estéticas tanto en el ámbito escolar como extraescolar.

La creatividad debe de ser calificada más como una actitud que como una aptitud. Se manifiesta cuando el individuo innova algo, crea, siendo satisfactorio para sí mismo, o cuando logra hacer relaciones de cosas que en su experiencia anterior no había podido hacer, encontrando el resultado estimulante y gratificador. La creatividad, en este aspecto, puede significar, ser, un estilo de vida; y es, naturalmente, incompatible con el conformismo: lo que favorece a una de ellas, tiende a destruir a la otra.

Por lo general, nuestras sociedades no alientan la creatividad: las presiones sociales que favorecen el conformismo son tan fuertes que, incluso, llegan a sancionar, indirecta o directamente, a aquel que se desvíe de él. Una 
sociedad que sí la inculque, tendrá que incorporar un sistema de valores que conlleve una visión de cambio y de innovación.

La educación estética contribuye a que las personas logren, sin esfuerzo, las reglas de la diversidad y la plenitud; les ayuda a concebir la belleza no como mercancía; disuelve las divisiones que puedan encontrarse dentro de lo estético y, también, dentro de la sociedad, si hombres y mujeres crean juntos una vida social significativa en la que el arte no se evalúe como una técnica especializada, tampoco como un saber exclusivo, sino, más bien, como la capacidad universal de darle a la vida el alto valor que posee, tanto para las personas como individuos como para la sociedad como un todo vivo e integrado. 